\title{
Effect of Solidification Pressure on Interfacial Heat Transfer and Solidification Structure of 19Cr14Mn0.9N High Nitrogen Steel
}

\author{
Zhouhua JIANG, Hongchun ZHU, Huabing LI, ${ }^{*}$ Guohai LIU, Pengbo WANG, Junhui ZHU, Shucai ZHANG and \\ Hao FENG
}

School of Metallurgy, Northeastern University, Shenyang, 110819 China.

(Received on June 30, 2017; accepted on August 22, 2017; J-STAGE Advance published date: November 7, 2017)

\begin{abstract}
The effect of solidification pressure $(0.5,0.85$ and $1.2 \mathrm{MPa})$ on heat transfer between ingot and mould was investigated with the measurement of cooling curves and calculation of heat transfer coefficient. Combined with cooling rate, temperature gradient and local solidification time (LST), the influence of pressure on solidification structure of $19 \mathrm{Cr} 14 \mathrm{Mn} 0.9 \mathrm{~N}$ was revealed by macrostructure observation. The calculation results of heat transfer coefficient, obtained by the Beck-Nonlinear estimation technique, indicate that increasing solidification pressure obviously enhances heat transfer at the ingot/mould interface. And higher solidification pressure is benefit to increase cooling rate and temperature gradient of ingot. Meanwhile, increasing solidification pressure considerably suppresses nitrogen gas pore, and reduces the whole area of dispersing porosity and shrinkage, which is favorable to obtain a sound ingot. With the solidification pressure increasing from 0.5 to $1.2 \mathrm{MPa}$, the columnar zone is lengthened, the columnar-toequiaxed transition (CET) position gradually moves to the ingot center, and both dendritic arm spacing $\left(\lambda_{1}\right.$ and $\lambda_{2}$ ) and local solidification time (LST) gradually decrease. The solidification structure is significantly refined and compressed under higher solidification pressure.
\end{abstract}

KEY WORDS: solidification pressure; high nitrogen steel; heat transfer coefficient; columnar-to-equiaxedtransition; dendritic arm spacing; shrinkage porosity.

\section{Introduction}

It is well documented that the interstitially dissolved nitrogen can effectively improve the mechanical properties and corrosion resistance of high-nitrogen steels (HNSs). ${ }^{1-4)}$ As such, a series of typical HNSs have been developed recently, such as CRONIDUR 30, M340, P900N and P2000. ${ }^{5,6)}$ However, the beneficial influence of nitrogen is usually limited by its low solubility in some steels, ${ }^{3,4)}$ which can result in serious nitrogen segregation and nitrogen pore defect during the melting and solidification of HNSs. Many thermodynamic studies ${ }^{4,7-10)}$ suggested that increasing nitrogen partial pressure was able to enhance the solubility of nitrogen and effectively eliminate pore defects for a given HNS. Therefore, the pressurized metallurgy has been considered as a promising method to obtain melt with high nitrogen content and keep nitrogen dissolved during the solidification of HNSs. ${ }^{4}$ Until now, several kinds of pressurized metallurgy technologies have been developed to manufacture HNSs, including pressurized induction melting (PIM) and pressurized electroslag remelting (PESR) et al. ${ }^{11-15)}$

Meanwhile, the pressure exhibits a significant impact on casting solidification and structure formation. ${ }^{15-17)}$ The

\footnotetext{
* Corresponding author: E-mail: huabing_li@163.com

DOI: http://dx.doi.org/10.2355/isijinternational.ISIJINT-2017-356
}

effect of the pressurization includes (a) increasing the solidification nucleation rate, (b) reducing the critical nucleus radius, (c) accelerating the cooling rate, ${ }^{18,19)}$ (d) refining macro/micro-structure, ${ }^{16,20}$ and (e) eliminating solidification defects (shrinkage, porosity and pore, et al.). ${ }^{16,17,19,21-23)}$ Although some researchers have studied the influence of pressure on the solidification structure, they mainly focus on the nonferrous metal, ${ }^{19,24,25)}$ only a few work has been carried out on HNSs. ${ }^{16,19,20)}$ Gavrilova et al. ${ }^{20)}$ has proposed that a small increment of pressure (several $\mathrm{MPa}$ ) can significantly increase heat transfer coefficient and refine the casting structure of HNSs. Zhu et al., ${ }^{26)}$ using CAFE method to investigate the effect pressure on compactness degree of high nitrogen steel, has concluded that higher solidification pressure is favourable to increase the number of grains of the whole ingot and reduces the primary dendrite arm spacing of central equiaxed. However, there is a lack of experimental study on relationship between solidification pressure and dendritic structure. Additionally, the pressure is one of key factors related to the occurrence of solidification defects, such as shrinkage, porosity and pore. Kubo ${ }^{27)}$ and Gupta et al. ${ }^{28)}$ reported that gas pores form because of the positive pressure created by gases dissolved in molten alloys, and shrinkage porosity occurs from the pressure drop during interdendritic fluid flow. The shrinkage, porosity and pore, caused by supersaturation of gas (mainly nitrogen), have been some kinds of major problems in solidification 
structure of HNSs. ${ }^{22,29)}$ But there are scarcely any experimental studies on shrinkage, porosity and pore of HNSs manufactured by pressurized metallurgy.

The present research aims to reveal the effect of solidification pressure on the interfacial heat transfer and solidification structure of a $19 \mathrm{Cr} 14 \mathrm{Mn} 0.9 \mathrm{~N}$ high nitrogen steel. The measurement of cooling curves was applied to obtain the values of heat transfer coefficient under different pressure, based on Beck-Nonlinear estimation technique and Visual Fortran (VF). Combining with the obtained cooling rate and temperature gradient of ingot, the influence of pressure on shrinkage, porosity and pore was clarified. Macrostructure observation was performed to analyze the tendency of columnar-to-equiaxed transition (CET), dendrite arm spacing and local solidification time (LST) with solidification pressure.

\section{Experimental Procedures}

Three 19Cr14Mn0.9N ingots were smelted under about $0.3 \mathrm{MPa}$ by a $25-\mathrm{kg}$ pressurized induction furnace. The pouring temperatures were $1823 \mathrm{~K}$. The solidification process of three ingots was achieved in cast iron mould (Fig. 1) under the different nitrogen pressures $(0.5,0.85$ and 1.2 $\mathrm{MPa})$. In order to eliminate the influent of pressure increment from smelting to solidification on the nitrogen contents of three ingots, the inflation and pouring process should be completed within five minutes. The chromium nitride $\left(\mathrm{Cr}_{2} \mathrm{~N}\right)$ was used to increase the nitrogen content, and whose additive contents decreased with the increment of solidification pressure $\left(P_{s}\right)$ to keep nitrogen contents approximately consistent in three ingots (Table 1). The nitrogen content of $19 \mathrm{Cr} 14 \mathrm{Mn} 0.9 \mathrm{~N}$ was detected by oxygen-nitrogen analyzer, and others were measured by optical emission spectrometry (OES), as shown in Table 1.

During solidification process, four double platinumrhodium thermocouples of " $\mathrm{B}$ " type were used to measure the cooling curves of ingot and mould at a height of 160 $\mathrm{mm}$ above the bottom of mould, as displayed in Fig. 1. The first $\left(T_{1}\right)$ and third $\left(T_{3}\right)$ thermocouples were inserted into the mould at 12 and $8 \mathrm{~mm}$ away from the mould inner wall, respectively. The second $\left(\mathrm{T}_{2}\right)$ and fourth $\left(\mathrm{T}_{4}\right)$ thermocouples were inserted into the ingot at 10 and $5 \mathrm{~mm}$ away from the mould inner wall, respectively. The cooling curves (1st, 2nd, 3rd and 4th) were obtained by a 16-channel data acquisition system.

The ingots were cut in axial direction by wire electrical discharge machining. The vertical sections of ingots were ground and then were recorded by a SONY $\alpha 5100$ camera to observe the pore defect, shrinkage and porosity. To observe the dendritic structure accurately, the $10 \times 10 \times 5$ $\mathrm{mm}$ specimens were cut at $115 \mathrm{~mm}$ away from the bottom of ingots, as shown in Fig. 1. All the specimens were polished with $1.5 \mu \mathrm{m}$ diamond paste, and then etched in a solution consisting of $1 \mathrm{~g} \mathrm{CuCl}_{2}, 0.2 \mathrm{~g} \mathrm{MgCl}_{2}, 1 \mathrm{~g} \mathrm{FeCl}_{3}, 6 \mathrm{ml} \mathrm{HCl}$, $60 \mathrm{ml} \mathrm{C}_{2} \mathrm{H}_{5} \mathrm{OH}, 50 \mathrm{ml} \mathrm{H}{ }_{2} \mathrm{O}$ for $1.5-2$ minutes at $298 \mathrm{~K}$. The dendrite morphology and dendrite arm spacing $\left(\lambda_{1}\right.$ and $\lambda_{2}$ ) were observed and investigated by Olympus DXS 510 digital microscope.

\section{Results and Discussion}

\subsection{Effect of Solidification Pressure on Interfacial Heat Transfer}

The temperature gradient $G$ and dendrite growth rate $R_{c}$ are greatly important for solidification structure, as the ratio $G / R_{c}$ affects the dendrite growth morphology and the cooling rate $V_{s}\left(=G R_{c}\right)$ determines the second dendritic arm spacing $\lambda_{2}{ }^{30-32)}$ The values of $G$ and $R_{c}$ depend markedly on the casting condition (superheat, mould materials,

Table 1. Chemical composition and solidification pressure of ingots.

\begin{tabular}{ccccccccccc}
\hline & \multirow{2}{*}{ Ingots } & $P_{s}$ & $\mathrm{Cr}_{2} \mathrm{~N}$ & \multicolumn{6}{c}{ Composition $(\mathrm{wt} \%)$} \\
\cline { 5 - 10 } & $(\mathrm{MPa})$ & $(\mathrm{kg})$ & $\mathrm{C}$ & $\mathrm{Si}$ & $\mathrm{Mn}$ & $\mathrm{N}$ & $\mathrm{Cr}$ & $\mathrm{Mo}$ & $\mathrm{Fe}$ \\
\hline 1 & 0.5 & 0.63 & 0.11 & 0.61 & 14.24 & 0.87 & 18.71 & 3.97 & Bal. \\
2 & 0.85 & 0.59 & 0.10 & 0.49 & 14.89 & 0.91 & 18.93 & 3.80 & Bal. \\
3 & 1.2 & 0.54 & 0.11 & 0.51 & 14.90 & 0.97 & 19.82 & 3.40 & Bal. \\
\hline
\end{tabular}

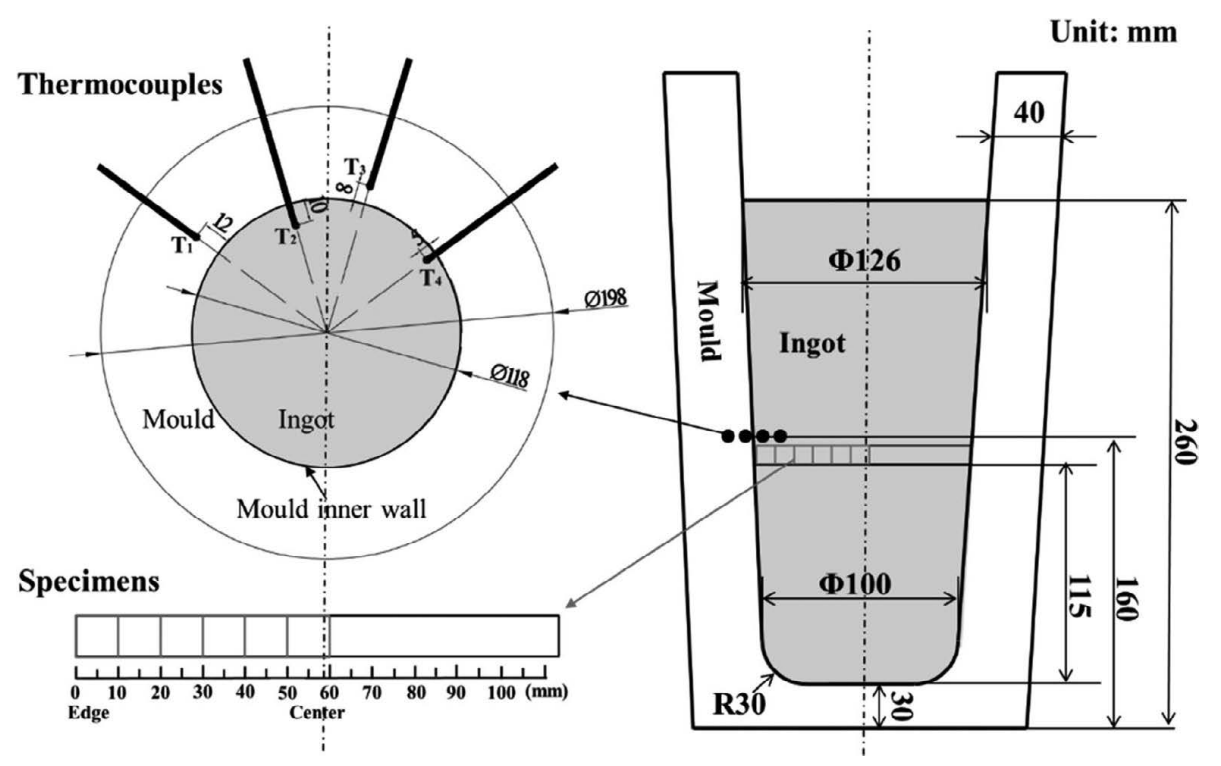

Fig. 1. Dimension of the mould and ingot, position of the thermocouples and specimens. 
distance from mould wall to ingot, i.e. air-gap, etc.). ${ }^{30)}$ In practice, the effect of casting condition on structure is usually described by the cooling rate $V_{s}$. calculated from the slope of cooling curve. ${ }^{30)}$ Figure 2 shows the cooling curves of casting under $0.5 \mathrm{MPa}$. In the initial stage, there are a sharp rise and oscillations of temperature in the 2nd and 4 th cooling curves, which are related to the thermocouple heating and turbulent liquid flow caused by the pouring. ${ }^{19)}$ As solidification continues, the ingot temperature (2nd and 4 th) decreases and that (1st and 3rd) of mould has a corresponding increase due to the transfer of heat from ingot to mould. There exists a huge gap between the 3rd and 4th cooling curves (Fig. 2), which is attributed to great thermal resistance $R_{\text {air-cap }}\left(=1 / h_{i}\right.$ ) caused by the air-gap at the ingot/ mould interface. Where, $h_{i}$ is the macroscopic average ingot/ mould interfacial heat transfer coefficient.

Among solidification processes of three $19 \mathrm{Cr} 14 \mathrm{Mn} 0.9 \mathrm{~N}$ ingots, the only difference is solidification pressure $(0.5$, 0.85 and $1.2 \mathrm{MPa}$ ), which impacts cooling rate $V_{s}$ by the dimensional change of air-gap. ${ }^{18,19,25)}$ Increasing solidification pressure reduces the size of the air-gap and accelerates the formation of the perfect contact, ${ }^{16)}$ which promotes the rate of mould temperature increase (1st and 3rd) and ingot temperature (2nd and 4th) decrease, as displayed in Fig. 3. When solidification pressure increases from 0.5 to 1.2 $\mathrm{MPa}$, the increments of average cooling rate in the 2 nd and 4th are 0.335 and $0.605 \mathrm{~K} / \mathrm{s}$, respectively. Meanwhile, the average temperature gradient between 2 nd and 4 th increases from 4.0 to $8.6 \mathrm{~K} / \mathrm{mm}$ at $300 \mathrm{~s}$. It indicates that the heat flux $Q_{\text {ingot }}$ in ingot increases with the pressure, based on Fourier's law of heat conduction ( $Q_{\text {ingot }}=k G$, where $k$ is the thermal conductivity of $19 \mathrm{Cr} 14 \mathrm{Mn} 0.9 \mathrm{~N})$. According to the law of energy conservation ( $Q=Q_{\text {ingot, }}$, where $Q$ is the average heat flux at ingot/mould interface), there is a corresponding enhancement of heat transfer at ingot/mould interface. Therefore, increasing solidification pressure accelerates the cooling rate of ingot and enhances the heat transfer from ingot to mould.

In order to further investigate the effect of solidification pressure on the heat transfer from ingot to mould, the heat transfer coefficient at the ingot/mould interface needs to be obtained. The interface is assumed to have no heat capacity,

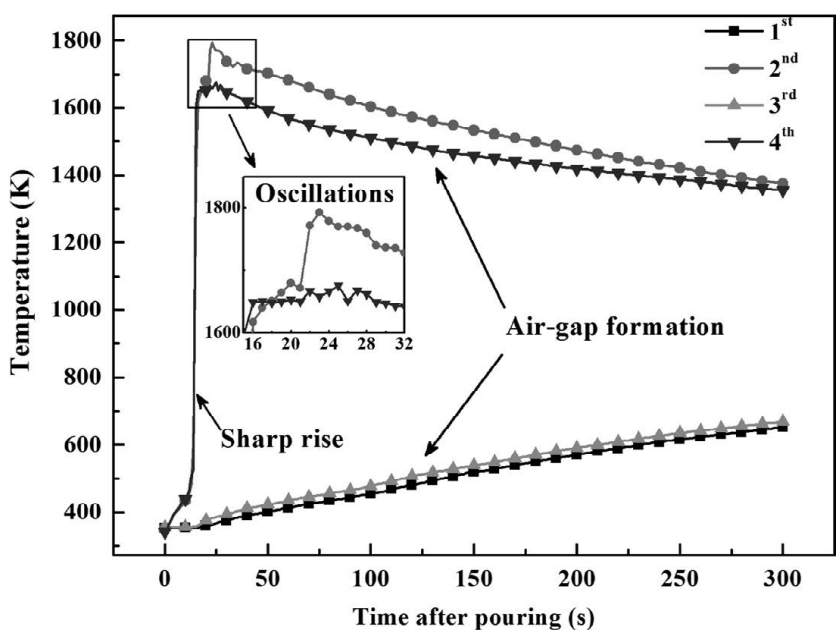

Fig. 2. Cooling curves of ingot (2nd and 4th) and mould (1st and 3rd) under 0.5 MPa. the macroscopic average ingot/mould interfacial heat transfer coefficient $\left(h_{i}\right)$ can be characterized by: ${ }^{19,33)}$

$$
h_{i}=\frac{Q}{T_{\mathrm{C}}-T_{\mathrm{M}}}
$$

where, $Q$ is the average heat flux across ingot/mould interface, $T_{\mathrm{c}}$ and $T_{\mathrm{M}}$ are the surface temperatures of ingot and mould, respectively. Considering radial flow of heat as dominant heat transfer direction, the temperature field of ingot and mould can be described by the one-dimensional form of general equation of heat conduction: ${ }^{19}$ )

$$
\rho C_{\mathrm{p}} \frac{\partial T}{\partial r}=\frac{1}{r} \frac{\partial}{\partial r}\left(k \frac{\partial T}{\partial r}\right)+q
$$

Where, $\rho$ is the density, $C_{\mathrm{p}}$ is the heat capacity, $q$ is the latent heat of solidification, $r$ is the radius, and $k$ is the thermal conductivity as shown in Table 2 . During the calcula-
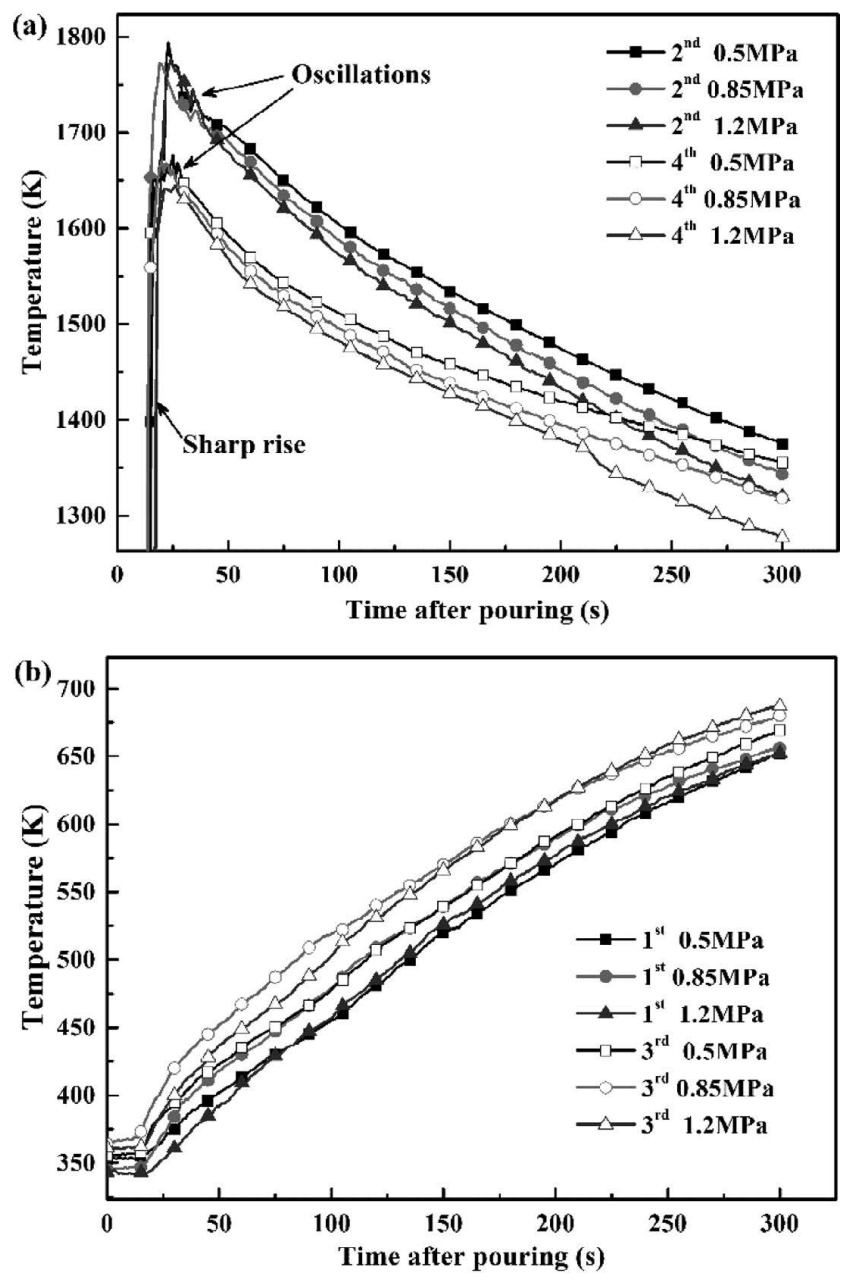

Fig. 3. Comparison of cooling curves of (a) ingot (2nd and 4th) and (b) mould (1st and 3rd) under different solidification pressures.

Table 2. Properties of ingot and mould used for the calculation.

\begin{tabular}{ccc}
\hline Properties & Ingot & Mould \\
\hline$\rho\left(\mathrm{kg} / \mathrm{m}^{3}\right)$ & 6901 & 7500 \\
$C_{p}(\mathrm{~J} / \mathrm{kg} \cdot \mathrm{K})$ & 808.25 & 700 \\
$k(\mathrm{~W} / \mathrm{m} \cdot \mathrm{K})$ & 33.94 & 40 \\
$q(\mathrm{~J} / \mathrm{kg})$ & 252000 & - \\
\hline
\end{tabular}


tion process of heat transfer coefficient at the ingot/mould interface, the 1 st and 2 nd cooling curves serve as the external boundary condition, and Eqs. (1) and (2) are solved by the Beck-Nonlinear estimation technique and Visual Fortran (VF). When the gap between calculation and experimental results of the $3 \mathrm{rd}$ and 4 th reaches a minimum value, the heat transfer coefficient $\left(h_{i}\right)$ is obtained. The detail calculation flowchart of the heat transfer coefficient is shown in Fig. 4.

Figure 5 shows the calculation results of heat transfer coefficients under $0.5,0.85$ and $1.2 \mathrm{MPa}$. As solidification

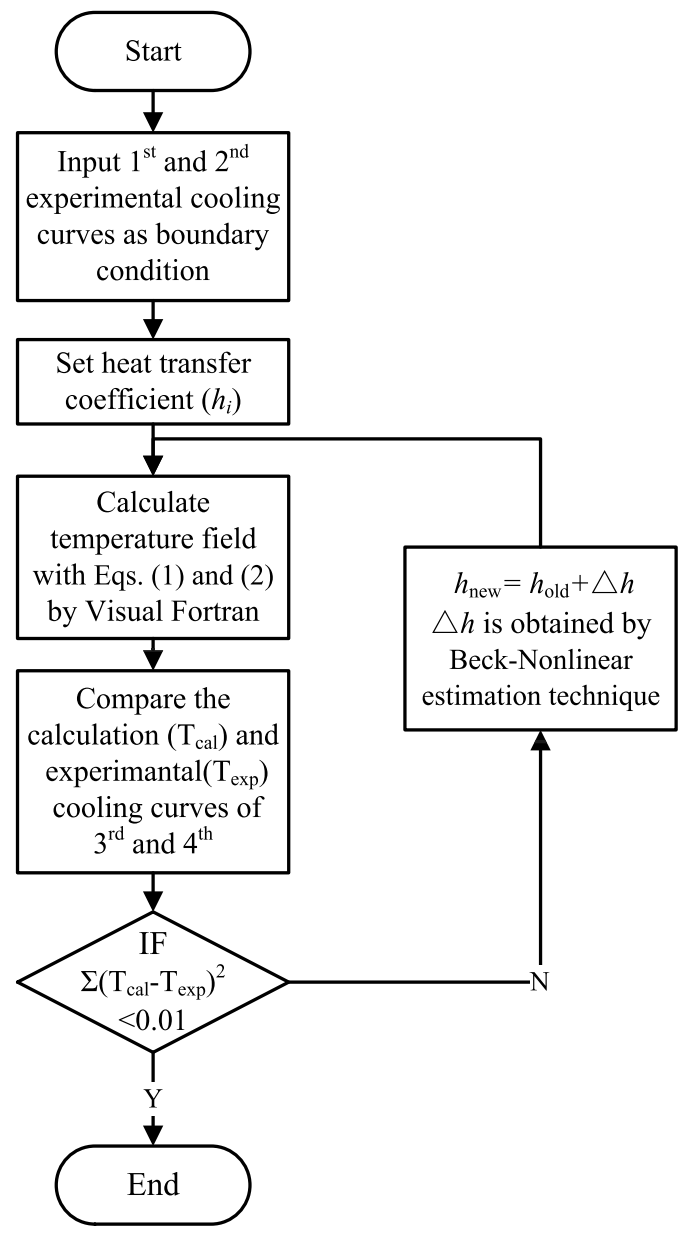

Fig. 4. Calculation flowchart of the heat transfer coefficient.

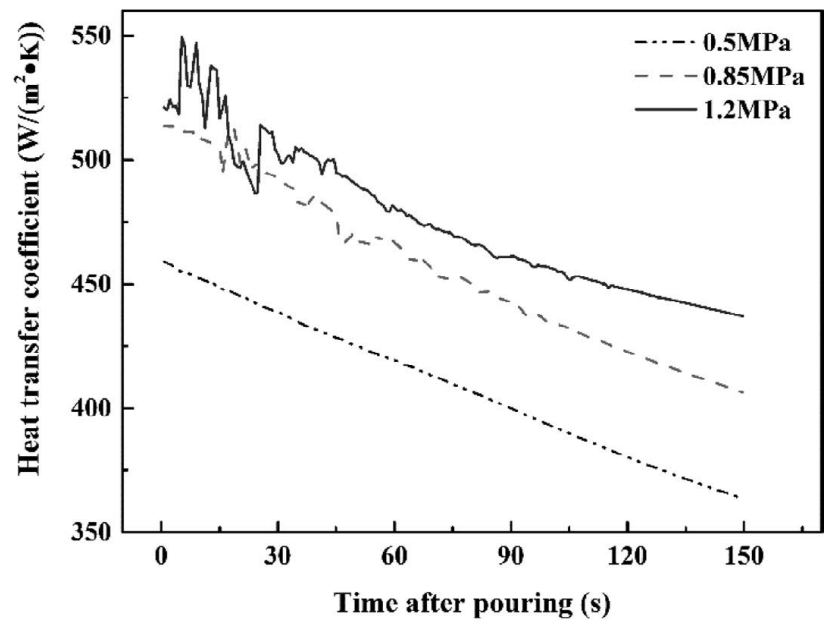

Fig. 5. Calculation result of heat transfer coefficient under different solidification pressures. process, the heat transfer coefficient gradually decreases at a given pressure, and it increases with solidification pressure. The tendency of heat transfer coefficient increase is obvious, just as the results of simulation and experiment reported by Ilkhchy and Aweda. ${ }^{19,34)}$ Thus, heat transfer from ingot to mould is improved considerably by applying solidification pressure load during ingot casting.

\subsection{Effect of Solidification Pressure on Shrinkage, Porosity and Pore}

Figure 6 shows the morphologies of shrinkage, porosity and pore under various solidification pressures $(0.5$, 0.85 and $1.2 \mathrm{MPa}$ ). Under $0.5 \mathrm{MPa}$, the large area of pore defect and dispersing porosity is found around the central line. With the increment of solidification pressure, the pore defect disappears, the whole area of shrinkage and dispersing porosity decrease obviously (Fig. 6(b)). When solidification pressure continually increases to $1.2 \mathrm{MPa}$, the whole area of dispersing porosity and concentrating shrink-
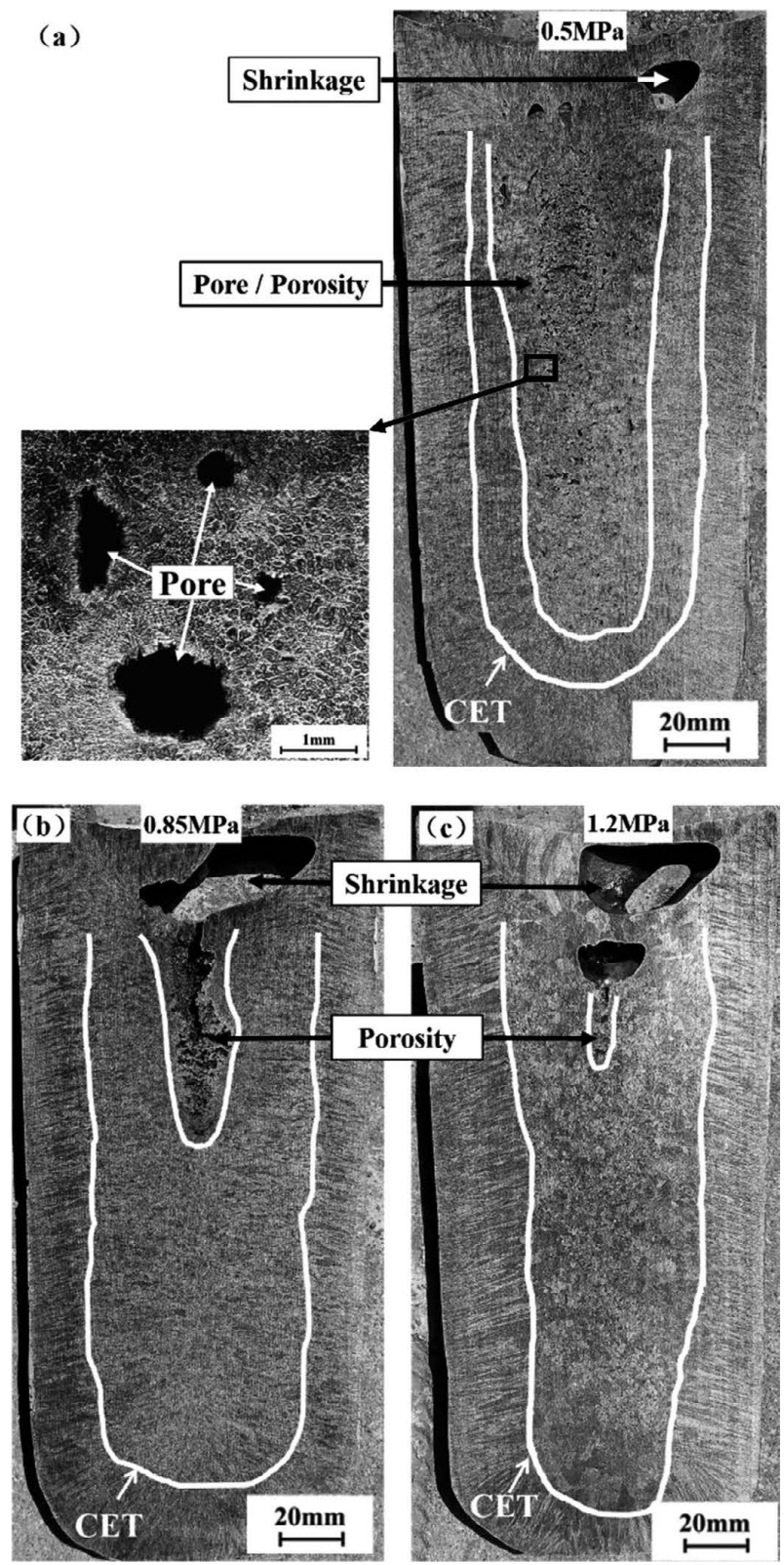

Fig. 6. Change tendency of pore, shrinkage, porosity and CET under (a) 0.5, (b) 0.85 and (c) $1.2 \mathrm{MPa}$. 
age further decreases. Those results reveal that increasing solidification pressure can considerably improve the quality of $19 \mathrm{Cr} 14 \mathrm{Mn} 0.9 \mathrm{~N}$ ingot by suppressing the formation of shrinkage, porosity and pore.

The change of dispersing porosity is closely related to interdendritic feeding. ${ }^{35)}$ With the increment of solidification pressure, both heat transfer coefficient and cooling rate increase, which results in the increase of temperature gradient $G$. Based on the criterion of constitutional supercooling, the degree of constitutional supercooling $\Delta G$ decreases with the increase of temperature gradient $G$, namely:

$$
\Delta G=m G_{c}-G
$$

Where, $m$ is liquidus slope. $G_{c}$ is concentration gradient With decreasing constitutional supercooling, the growth of secondary dendrite and formation of dendritic network become weakened, ${ }^{36)}$ and then interdendritic feeding resistance reduces. ${ }^{35)}$ Moreover, increasing solidification pressure from 0.5 to $1.2 \mathrm{MPa}$, the increments of liquidus and solidus temperature $\left(T_{L}\right.$ and $\left.T_{S}\right)$ are so small that they could be neglected in the present investigation, according to the calculation results by Thermo-Calc software as shown in Fig. 7. So the solidification range $\left(T_{L}-T_{S}\right)$ of $19 \mathrm{Cr} 14 \mathrm{Mn} 0.9 \mathrm{~N}$ remains approximately constant under three solidification pressures. And the length of mushy zone $X\left(=\left(T_{L}-T_{S}\right) / G\right)$ decreases with the increment of solidification pressure, ${ }^{37)}$ implying that the interdendritic feeding distance becomes shorten. Therefore, increasing solidification pressure enhances interdendritic feeding by decreasing interdendritic feeding resistance and the length of mushy zone, and then reduces the whole area of dispersing porosity and shrinkage (Fig. 6).

Figure 6(a) shows the enlarged view of the pore defect whose position is $115 \mathrm{~mm}$ height above ingot bottom and 5 $\mathrm{mm}$ away from the center under $0.5 \mathrm{MPa}$. The appearance of pore defects varies between typical round nitrogen gas pores and those with a shape of shrinkage pores, and it is reasonable to assume that both the presence of nitrogen gas and shrinkage contribute to pore formation. ${ }^{22)}$ The nucleation of nitrogen gas pore is mainly effected by the pressure inside the nitrogen gas pore $P_{g}$, the melt pressure $P_{m}$, the solidification pressure $P_{s}$, and the capillary pressure $P_{c}$. When $P_{g}$ is

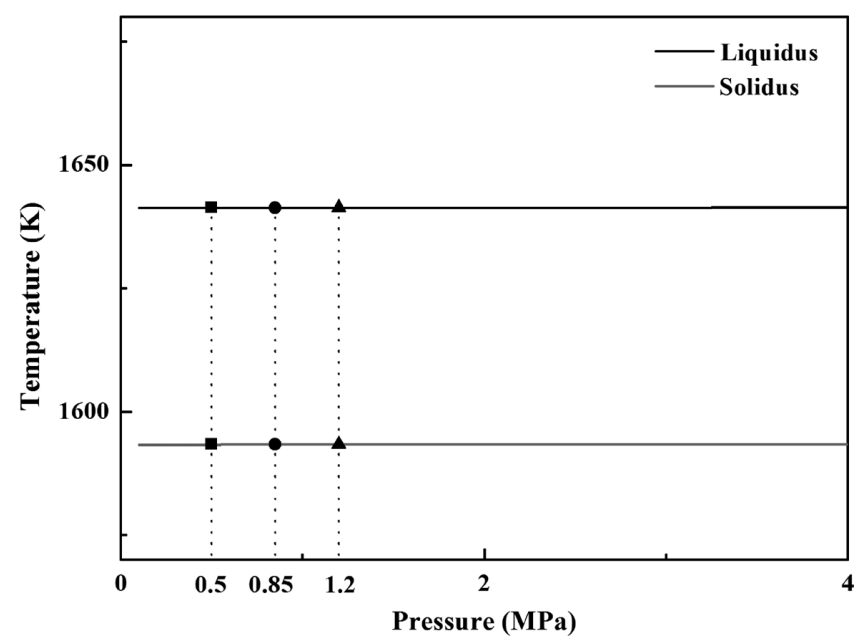

Fig. 7. Change of liquidus/solidus temperature with solidification pressure. exceeded by the sum of $P_{m}, P_{s}$ and $P_{c}$, the nitrogen gas pore can nucleate and grow, namely: $:^{7,35)}$

$$
P_{g}>P_{S}+P_{m}+P_{c}
$$

It is obvious that the increase of solidification pressure is greatly helpful to make the addition of $P_{m}, P_{s}$ and $P_{c}$ overcome $P_{g}$, which can suppress the nucleation of nitrogen gas pore. ${ }^{22)}$ So, increasing solidification pressure is an effective method to prevent the nucleation of nitrogen gas pore. At the beginning of solidification, $P_{m}$ is equivalent to the hydrostatic pressure of the melt. When the solidification shrinkage sucks the melt through interdendritic space, there exists a pressure drop of $P_{m}$. With more complex dendritic network, $P_{m}$ may become so negative that it promotes the formation of nitrogen gas pore. ${ }^{21,22)}$ In addition, the increase of solidification pressure $\left(P_{s}\right)$ is conducive to 'inject' melt into the interdendritic space or shrinkage microcavities, ${ }^{22}$ ) and then compensates for the decrement of $P_{m}$ to suppress the formation and growth pore defect according to Eq. (4). ${ }^{7)}$ Therefore, the increase of solidification pressure is effective to decrease the formation tendency of pore defect to ensure a sound casting (Fig. 6(c)).

\subsection{Effect of Solidification Pressure on Dendrite Structure}

The ingot presents two typical macrostructures: columnar dendrites and equiaxed grains, which can be described by two important features (columnar-to-equiaxed-transition (CET) and dendrite arm spacing). ${ }^{38,39)}$ Figure 6 shows the CET position of ingots solidified under different solidification pressure. For $0.5,0.85$ and $1.2 \mathrm{MPa}$, the statistical average distances between CET and the edge of ingot are 19.8, 22.1 and $27.4 \mathrm{~mm}$, respectively. It indicates that the CET is postponed with increasing solidification pressure. There is a hard blocking criterion on the occurrence of CET. ${ }^{40)}$ If the volume fraction of equiaxed grains ahead of a columnar front is beyond the critical threshold, the tip growth of columnar dendrites is delayed, and the CET occurs. ${ }^{38)}$ So, the CET is largely dependent on the nucleation and growth of equiaxed grains. Due to the cooling rate accelerated by increasing solidification pressure, the temperature gradient is higher and the constitutional undercooling is limited under higher solidification pressure. In this case, the nucleate and grow of equiaxed grains ahead of a columnar front is seriously inhibited. ${ }^{36,39,41,42)}$ By contrast, decreasing the solidification pressure, the condition is more favorable for the nucleation and growth of equiaxed grains, and the occurrence of CET becomes much easier. ${ }^{35)}$ Thus, the length of the columnar zone increases and CET position gradually moves to the central line of the ingot with increasing solidification pressure from 0.5 to $1.2 \mathrm{MPa}$.

At each height, the size of dendritic arm spacing exhibits an increasing tendency from the edge to center of ingot. So, the positions at $115 \mathrm{~mm}$ height above the bottom of three ingots are chosen to investigated the change of primary dendritic arm spacing $\left(\lambda_{1}\right)$ and second dendritic arm spacing $\left(\lambda_{2}\right)$ with different solidification pressure. Since the equiaxed grains grow roughly equally in all directions (equally along all their axes) and firmly connect with each other, the $\lambda_{1}$ of equiaxed grains is difficult to measure, and the $\lambda_{1}$ of columnar dendrites was investigated before CET. Figure 8 dis- 
(a)
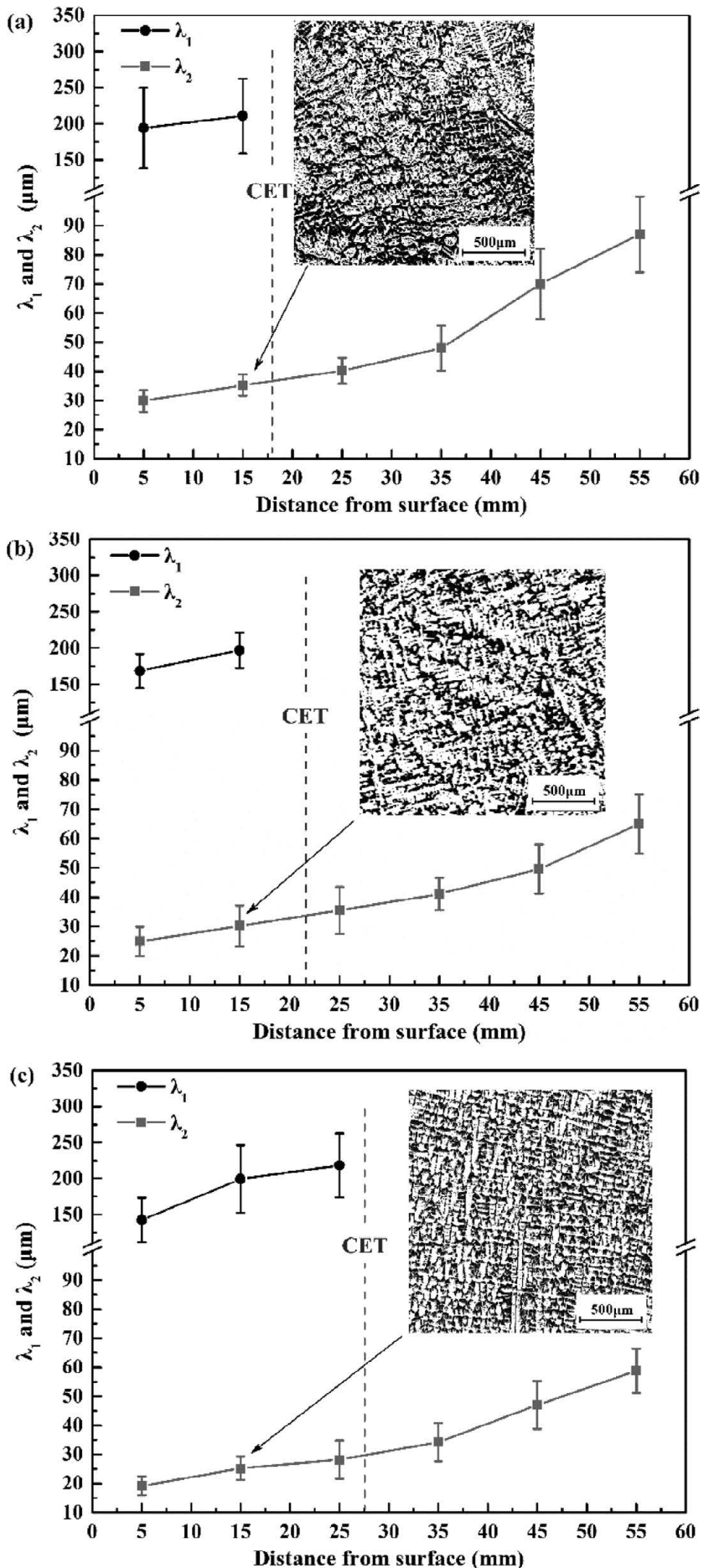

Fig. 8. Distribution of dendritic arm spacing $\left(\lambda_{1}\right.$ and $\left.\lambda_{2}\right)$ under (a) 0.5 (b) 0.85 and (c) $1.2 \mathrm{MPa}$.

plays the change of dendritic arm spacing $\left(\lambda_{1}\right.$ and $\left.\lambda_{2}\right)$ under $0.5,0.85$ and $1.2 \mathrm{MPa}$. Both $\lambda_{1}$ and $\lambda_{2}$ gradually increase from edge to center of three ingots. In addition, they both exhibit a decreasing tendency with increasing solidification pressure at the same position, indicating that the solidification structure is refined under higher solidification pressure.

The dendritic arm spacing $\left(\lambda_{1}\right.$ amd $\left.\lambda_{2}\right)$ is related to dendrite growth rate $R_{c}$ and temperature gradient $G$, namely: $:^{31,32,43)}$

$$
\lambda_{1}=\frac{N}{G^{l} R_{c}^{m}}, \lambda_{2}=M \cdot \mathrm{LST}
$$

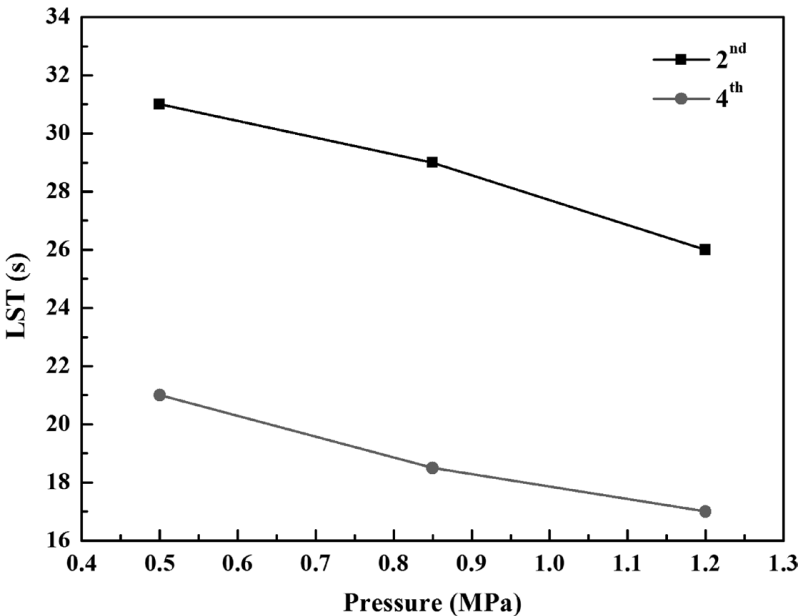

Fig. 9. Change of LST in the position of 2nd and 4th.

Where $N, l, m$ and $M$ are parameters which depend mainly on the alloy composition. And $\lambda_{1}$ decreases with the increase of cooling rate, and $\lambda_{2}$ decreases with the decrease of LST. LST is the local solidification time. The relationships among these solidification parameters are:

$$
\mathrm{LST}=\frac{X}{V_{s}}, R_{c}=\frac{V_{s}}{G}, G=\frac{T_{L}-T_{S}}{X}
$$

Where $X$ is the length of mushy zone. LST can be obtained by the following equation:

$$
\mathrm{LST}=\frac{T_{L}-T_{S}}{R_{c} G}=\frac{T_{L}-T_{S}}{V_{S}}
$$

Based on this, LST can be obtained form 2nd and 4th cooling curves, and decreases with increasing solidification pressure, as shown in Fig. 9. So, increasing solidification pressure can decrease dendritic arm spacing $\left(\lambda_{1}\right.$ amd $\left.\lambda_{2}\right)$ and refine the solidification structure by increasing cooling rate and decreasing LST. Meanwhile, the change of dendrite morphology (Fig. 8) also exhibits that increasing solidification pressure plays a very important role in the refinement of solidification structure, just as reported by Sobczak. ${ }^{16)}$

\section{Conclusions}

The influence of pressure on interfacial heat transfer and solidification structure of $19 \mathrm{Cr} 14 \mathrm{Mn} 0.9 \mathrm{~N}$ high nitrogen steel were investigated by combination experimental and calculation results. The main conclusions can be obtained as follows.

(1) The increment of solidification pressure considerably enlarges the heat transfer coefficient at the ingot/mould interface, and then increases the cooling rate and temperature gradient of $19 \mathrm{Cr} 14 \mathrm{Mn} 0.9 \mathrm{~N}$ ingot.

(2) Increasing solidification pressure, the nitrogen gas pore gradually disappears and the whole area of dispersing porosity and shrinkage obviously reduces. It suggests that the increase of solidification pressure is an effective method to obtain a sound casting.

(3) When increasing solidification pressure from 0.5 to 1.2 $\mathrm{MPa}$, the length of the columnar zone increases and CET position gradually moves to the central line of ingot. At the same time, both dendritic arm spacing $\left(\lambda_{1}\right.$ and $\left.\lambda_{2}\right)$ and local solidification time (LST) exhibit a decreasing tendency, 
indicating that the solidification structure is refined under higher solidification pressure.

\section{Acknowledgments}

This work was supported by the National Nature Science Foundation of China (grant numbers 51434004, U1435205 and 51304041) and the Fundamental Research Funds for the Central Universities (grant number N150204007).

\section{REFERENCES}

1) Z. H. Jiang, H. B. Li, Z. P. Chen, Z. Z. Huang, D. L. Zou and L. K. Liang: Steel Res. Int., 76 (2005), 740.

2) H. B. Li, Z. H. Jiang, Y. Yang, Y. Cao and Z. R. Zhang: Int. J. Miner. Metall. Mater., 16 (2009), 517.

3) H. Feichtinger and G. Stein: Mater. Sci. Forum, 318 (1999), 261

4) G. Stein and I. Hucklenbroich: Mater. Manuf. Process., 19 (2006), 7.

5) B. Reynders and M. Stratmann: Mater. Sci. Forum, 185-188 (1995), 731.

6) G. Stein, I. Hucklenbroich and M. Wagner: Mater. Sci. Forum, 318-320 (1999), 167.

7) S. H. Yang and Z. H. Lee: Mater. Sci. Eng. A, 417 (2006), 307.

8) R. G. Blossey and R. D. Pehlke: Metall. Trans., 2 (1971), 3157.

9) J. J. Pak, Y. S. Jeong, S. J. Tae, D. S. Kim and Y. Y. Lee: Metall. Mater. Trans. B, 36 (2005), 489.

10) H. Wada and R. D. Pehlke: Metall. Trans. B, 12 (1981), 333.

11) B. E. Paton and L. B. Medovar: Steel Transl., 38 (2008), 1028.

12) H. B. Li, Z. H. Jiang, Q. F. Ma and W. M. Li: Appl. Mech. Mater., 52-54 (2011), 1687.

13) Y. C. Jeon and K. T. Kim: Int. J. Mech. Sci., 41 (1999), 815.

14) T. E. Gammal, R. Abdel-Karim, M. T. Walter, E. Wosch and S. Feldhaus: ISIJ Int., 36 (1996), 915.

15) Z. H. Jiang, H. C. Zhu, H. B. Li, Y. Li and F. B. Liu: Proc. 2015 Int. Symp. Liquid Metal Processing and Casting, Austrian Society for Metallugy and Materials, Leoben, (2015), 536.

16) J. J. Sobczak, L. Drenchev and R. Asthana: Int. J. Cast Met. Res., 25 (2012), 1

17) Z. Han, H. Pan, Y. Li, A. A. Luo and A. K. Sachdev: Metall. Mater. Trans. B, 46 (2014), 328.

18) J. A. Sekhar, G. J. Abbaschian and R. Mehrabian: Mater. Sci. Eng., 40 (1979), 105.

19) A. F. Ilkhchy, M. Jabbari and P. Davami: Int. Commun. Heat Mass Transf., 39 (2012), 705.
20) R. Gavrilova, V. Manolov, A. Yotova, S. Popov and L. Saraivanov: Proc. 4th Int. Cong. on 'Mechanical Engineering Technologies', Department of Design \& Faculty of Technology, Varna, Bulgaria, (2004), 135

21) M. R. Ridolfi and O. Tassa: Intermetallics, 11 (2003), 1335.

22) R. Arola, J. Wendt and E. Kivineva: Mater. Sci. Forum, 318-320 (1999), 297.

23) R. D. Li, Z. P. Huang, Y. H. Bai, Q. S. Zhang and H. F. Zhang: Foundry, 52 (2003), 92.

24) J. Swan, M. Ward and R. C. Reed: Mater. Sci. Forum, 765 (2013), 276.

25) W. D. Griffiths and K. Kawai: J. Mater. Sci., 45 (2010), 2330

26) H. C. Zhu, Z. H. Jiang, H. B. Li, J. H. Zhu, H. Feng, S. C. Zhang, B. B. Zhang, P. B. Wang and G. H. Liu: Steel Res. Int., (2017), DOI: 10.1002/srin.201600509.

27) K. Kubo and R. D. Pehlke: Metall. Trans. B, 16 (1985), 359.

28) A. Gupta, B. Saxena, S. Tiwari and S. Malhotra: J. Mater. Sci., 27 (1992), 853.

29) S. H. Yang and Z. H. Lee: Mater. Sci. Eng. A, 417 (2006), 307.

30) N. Suutala: Metall. Trans. A, 14 (1983), 191.

31) J. M. Cabrera-Marrero, V. Carreño-Galindo, R. D. Morales and F. Chávez-Alcalá: ISIJ Int., 38 (1998), 812.

32) M. El-Bealy and B. G. Thomas: Metall. Mater. Trans. B, 27 (1996), 689.

33) F. Bertelli, N. Cheung and A. Garcia: Appl. Therm. Eng., 61 (2013), 577.

34) J. O. Aweda and M. B. Adeyemi: J. Mater. Process. Technol., 209 (2009), 1477.

35) M. C. Flemings: Solidification Processing, Mcgraw-Hill College, New York, (1974), 239.

36) W. Kurz and D. J. Fisher: Fundamentals of Solidification, Trans Tech., Switzerland, (1986), 53.

37) P. K. Penumakala, A. K. Nallathambi, E. Specht, U. Urlau and P. Unifantowicz: Appl. Therm. Eng., 84 (2015), 286.

38) M. Wu and A. Ludwig: Metall. Mater. Trans. A, 37 (2006), 1613.

39) A. E. Ares and C. E. Schvezov: Metall. Mater. Trans. A, 38 (2007), 1485 .

40) J. Li, M. Wu, A. Ludwig and A. Kharicha: Int. J. Heat Mass Transf., 72 (2014), 668.

41) P. Lan, H. Tang and J. Zhang: Metall. Mater. Trans. A, 47 (2016), 1.

42) D. M. Stefanescu: Science and Engineering of Casting Solidification, Springer International Publishing, New York, (2015), 185.

$43)$ V. K. D. Barcellos, V. L. D. S. Gschwenter, H. Kytönen, C. A. D. Santos, J. A. Spim, S. Louhenkilpi and J. Miettinen: Steel Res. Int., 81 (2010), 461. 